\title{
ANÁLISIS DEL IMPACTO DE LA SERIE DE TELEVISIÓN "ISABEL" EN EL TURISMO CULTURAL DE CASTILLA Y LEÓN
}

\author{
M. Ángeles López Ronco y Jorge del Caz Martín \\ Universidad Rey Juan Carlos, España
}

\begin{abstract}
Resumen: Isabel I de Castilla, "La Católica", siempre ha sido un personaje admirado y rechazado a partes iguales. Sin embargo, en los últimos años ha surgido un creciente interés por conocer su vida y, principalmente, los sitios que formaron parte de su historia. El nacimiento de este fenómeno reside en el éxito que tuvo la serie de televisión "Isabel", emitida en España entre 2012 y 2014, que se centró en la biografía de esta reina mostrando los diferentes lugares en los que vivió. Con todo, esto tuvo una repercusión en el turismo, sumándose esta ficción a la tendencia de emplear la aparición de un destino turístico en series de televisión como herramienta para su promoción, tal y como se ha demostrado con el buen impacto que la serie causó en el turismo cultural de Castilla y León, favoreciendo al crecimiento de la oferta turística de la comunidad y a la mejora de las estadísticas de llegada de visitantes.
\end{abstract}

Palabras clave: Turismo cultural, ruta, itinerario, movie tourism, destino turístico, serie televisiva, promoción, visitante.

Abstract: Queen Isabel of Castile, known as the Catholic, has always been admired and rejected in equal measure. However, in recent years there has been growing interest in knowing about his life and about the places that were part of its story. The birth of this phenomenon is to be found in the success of the television series "Isabel", broadcast in Spain between 2012 and 2014, which focused on the biography of this queen and showed the different places where she lived. In addition, this had an impact on tourism, adding this fiction to the tendency to use the appearance of a tourist destination in television series as a promotional tool, as it has been demon-

Recibido: 18-02-2018. Aceptado: 08-11-2019. 
strated with the good impact that the series caused in the cultural tourism of Castile and Leon, favouring the growth of the tourist offer of the community and the improvement of the statistics of arrival of visitors.

Keywords: Cultural tourism, route, itinerary, movie tourism, tourist destination, TV series, promotion, visitor.

\section{Introducción}

En los últimos años, se ha desarrollado un nuevo paradigma en el campo turístico a raíz de un cambio de comportamiento en la sociedad actual, convertida en una auténtica consumidora de series de televisión. Envuelto en la ficción que crea la serie, el espectador se convierte en un potencial turista que busca recorrer los distintos lugares en los que se ha rodado o transcurre la trama. A pesar de que se han llevado a cabo numerosas investigaciones que han demostrado la correlación entre el éxito de audiencia y la mejora de la oferta y demanda de un destino turístico que ha sido visualizado en pantalla, se han basado principalmente en ficciones internacionales. En este sentido, se hace necesario un estudio para tratar de demostrar si este fenómeno también puede ser extrapolado al caso de España con una serie nacional, tomando como ejemplo 'Isabel' y como región de estudio la comunidad de Castilla y León.

Esta investigación se centra en un personaje histórico cuya biografía siempre ha suscitado interés y polémica. No obstante, se trata de comprobar si el éxito de la serie sobre su vida, ha mejorado el perfil bajo que arrastraba Isabel La Católica por los diferentes hitos políticos y sociales que acontecieron durante su reinado. En este sentido, si el espectador conseguía superar el estigma negativo y se interesaba por los lugares que formaron parte de la vida de esta reina, se puede decir que la ficción televisiva ha conseguido reforzar el turismo en los destinos turísticos ligados a ella.

Del mismo modo, a través de este estudio se pone de manifiesto cómo el turismo cultural es una pieza clave del rompecabezas turístico de Castilla y León, una región que en los últimos años se viene interesando en la explotación de la vertiente histórica de sus recursos turísticos, aprovechando el valor que personajes como la reina Isabel La Católica tienen en su historia, así como el importante patrimonio cultural que atesora. Los productos turísticos que surgieron en Castilla y León a raíz de la emisión de la serie "Isabel" se basaron principalmente en diversas rutas turísticas en torno a la figura de la soberana. La más importante de todas fue el itinerario propuesto por la Junta de Castilla y León, conocido como "Ruta de Isabel en Castilla y León", que aúna, en definitiva, al resto de productos locales bajo una misma marca.

El objetivo primordial de este trabajo es determinar el impacto que la serie de televisión "Isabel" ha tenido en el turismo cultural de Castilla y León, llevando a cabo 
una cuantificación del mismo en términos de oferta y demanda turística, comparando la situación anterior y posterior a la emisión de esta ficción televisiva. El objeto de estudio es si la aparición de un destino turístico en una serie de televisión, puede servir como herramienta para su promoción.

Para ello, la metodología utilizada ha respondido a la revisión de diversas fuentes bibliográficas relacionadas con el tema objeto de análisis, a fin de asentar las bases teóricas de la investigación, analizando conceptos como el movie tourism o turismo inducido por el cine, la convergencia entre la industria audiovisual y la turística o las motivaciones de los viajeros desde el punto de vista de la psicología social del turismo. Por otro lado, se ha utilizado como fuentes primarias el contacto directo con los agentes turísticos del destino, que han aportado una visión fidedigna de los posibles cambios acontecidos en los destinos que han sido escenario de la serie.

\section{2. Área de estudio}

La razón de haber escogido Castilla y León y no otra comunidad autónoma, como podría haber sido Andalucía o Extremadura, en las cuales también se aprecia la huella isabelina, es que la reina Isabel nació y falleció en Castilla y León, además de ser esta región la herencia actual de la Corona de Castilla sobre la que ella gobernó y reinó de manera personal durante treinta años, desde 1474 hasta 1504. Del mismo modo, es importante destacar que la gran mayoría de las escenas que se visualizan en la serie sobre su vida están ambientadas en diferentes rincones de esta comunidad.

Por otra parte, sobre Castilla y León hay que subrayar que es definida en su Estatuto de Autonomía como una comunidad autónoma "histórica y cultural" que "ha contribuido de modo decisivo a la formación de España como nación”. Este legado ha permitido que la comunidad aventaje al resto del país en lo que a patrimonio cultural se refiere, ya no solo en términos reales por el inventario patrimonial con el que cuenta, sino también en concepto de inversión. Según el Plan PAHIS 2020 del Patrimonio Cultural de Castilla y León, la región cuenta con más de dos mil BIC que se reparten en alrededor de 750 municipios, lo que hace que en Castilla y León haya aproximadamente un BIC por cada 50 $\mathrm{km}^{2}$. Algunos expertos determinan que en esta comunidad se encuentra el 50\% del patrimonio cultural español (Miguel Recio, 2002), llegando a listar desde la propia Junta en 112 los conjuntos históricos, 11 catedrales y una concatedral, más de 500 castillos, una de las mayores concentraciones mundiales de arte románico, cerca de 400 museos y el paso de vías históricas como la de la Plata o el Camino de Santiago.

Gracias a este extenso inventario patrimonial, la comunidad ha podido sumarse a la carrera de la denominada economía del patrimonio cultural, es decir, ha conseguido que los bienes del patrimonio cultural dejen de ser percibidos como una carga para que 
sean considerados como un recurso capaz de generar desarrollo y cohesión social (Plan PAHIS 2020). En relación a lo anterior, algunos datos recogidos en el Plan PAHIS 2020 demuestran este logro en base a los objetivos alcanzados por el anterior Plan PAHIS 2004-2012. Durante ese período, la inversión pública y privada en patrimonio cultural en la autonomía alcanzó los 500 millones de euros, un 1,23\% del presupuesto de la comunidad, mientras que la media nacional se situaba en $0,61 \%$. En términos de empleo, se creó una media anual de 1.320 puestos de trabajo directos relacionados con actuaciones sobre bienes patrimoniales de Castilla y León.

Por tanto, no es de extrañar que este legado histórico y patrimonial tan importante, haya supuesto el arraigo de un fuerte turismo cultural en la región en torno al mismo y que sea la causa de que esta actividad económica sea una de las fuentes de riqueza de su economía. Tomás Villanueva, presidente de la Fundación del Patrimonio Histórico de Castilla y León, afirma que "turismo y cultura han sido desde siempre áreas convergentes que han conseguido, aunando sus objetivos e intereses, impulsar una nueva demanda social y crear un nuevo espacio de consumo de servicios, en torno a lo que conocemos como turismo cultural" (Herrero Prieto, 2000, p. 25).

El turismo cultural nace íntimamente ligado al patrimonio cultural, por lo que su paulatina generalización en España explica que zonas de interior como Castilla y León se hayan convertido en un importante foco de atracción turístico. De hecho, según el Anuario de Estadísticas Culturales 2016, fue la tercera comunidad autónoma que más viajeros residentes en España recibió por motivos culturales, 1,2 millones, por detrás de Andalucía y la Comunidad de Madrid.

Sin embargo, uno de los grandes problemas del turismo cultural castellanoleonés radica en la dispersión de su patrimonio, sobre todo en las zonas rurales. Para afrontarlo, se ha recurrido a la creación de rutas culturales, organizadas en torno a programas atractivos que conectan diversos puntos de interés para que el turista aproveche al máximo su desplazamiento a través de un mismo hilo conductor (Herrero Prieto, 2000). Actualmente, la mayor parte de los recorridos culturales de la comunidad se ven ligados a su pasado histórico, puesto que en los últimos años la Junta de Castilla y León "avanza hacia la especialización de un turismo histórico, vinculado a personajes reales, relacionados con la historia de la comunidad y que son un referente universal"1.

Algunos ejemplos recientes y vigentes son la ruta Huellas de Santa Teresa presentada en 2014 en FITUR, la adhesión de la Junta de Castilla y León a la Red de Cooperación de las Rutas Europeas de Carlos V en noviembre de 2017 y, por supuesto, la crea-

\footnotetext{
1. Declaraciones de Javier Ramírez, director general de Turismo de la Junta de Castilla y León, en el acto protocolario de adhesión de la Junta a la Red de Cooperación de las Rutas Europeas del Emperador Carlos V, el 3 de noviembre de 2017.
} 
ción de la Ruta de Isabel en Castilla y León en 2012. Sobre esta última, el éxito de la serie de televisión "Isabel" y los diferentes lugares que, reales o recreados, eran observados en cada capítulo por los espectadores, motivaron un interés por conocer los emplazamientos que formaron parte de la vida de esta reina castellana. Las administraciones regionales y locales castellanoleonesas recogieron el testigo de esta oportunidad que había nacido en el mercado para incorporarla a su oferta turística.

Las estadísticas avalan la importancia que las rutas culturales tienen en el desarrollo turístico de Castilla y León. De acuerdo con el Boletín de Coyuntura Turística 2017 que publicó la Junta de Castilla y León, el 34,2\% de los viajeros que se acercaron ese año hasta Castilla y León lo hicieron para realizar un recorrido turístico, motivo que se convierte en el principal de los viajes a la comunidad. Además, el desplazamiento se produce en coche en su amplia mayoría (71\%) y, a la hora de describir su visita, el 65\% de los viajeros afirmó haber visitado sus monumentos.

Hay que destacar que, a diferencia de otros modelos turísticos como el de sol y playa, el turismo cultural viene acompañado por la idea de sostenibilidad en el entorno, lo cual no es excluyente de poder producir rentabilidad económica. Como actividad de la sociedad de consumo, es un sector económico capaz de generar riqueza que viene acompañado de actividades que pretenden mantener el patrimonio cultural, impulsar nuevos recursos turísticos y crear una imagen cultural de destino (Mallor, GonzálezGallarza y Fayos, 2013).

Con la promoción y desarrollo del turismo cultural en Castilla y León se han explotado recursos patrimoniales poco conocidos y separados entre sí, lo que ha permitido reinvertir las ganancias en su conservación, se ha diversificado la oferta turística y se han incrementado las estancias y los visitantes. Todo ello, ha permitido dinamizar las economías rurales de Castilla y León, que destacaban por su marcada tendencia agraria (García Zarza, 2002), conllevando, en última instancia, que el turismo cultural se haya configurado como una fuente de riqueza para toda la comunidad autónoma.

\section{Estudio de la oferta turística}

La serie de televisión "Isabel" jugó un activo papel en la diversificación de la oferta turística cultural en diferentes puntos de Castilla y León entre los años 2012 y 2013. De no haberse emitido esta ficción histórica, la mayor parte de las localidades que llevaron a cabo la creación de productos turísticos ligados al personaje histórico de Isabel La Católica nunca los hubieran desarrollado al no existir una motivación turística que atrajera a la demanda, como así era la producción televisiva sobre su vida. De hecho, anterior al estreno de su primera temporada en septiembre de 2012, no existían experiencias turísticas relacionadas con la reina en la mayor parte de las ciudades que posteriormente decidieron crearlas, así como tampoco la Ruta de Isabel en Castilla y León. 
Comenzando con el estudio de la oferta turística cultural de Castilla y León surgida a raíz de la emisión de la serie "Isabel", cabe destacar primeramente que la diversificación es un aspecto fundamental en un entorno marcado por la fuerte competencia, una solución clave para poder diferenciarse de otros destinos y generar nuevos recursos turísticos. Esta fue, de hecho, una de las justificaciones que Claudia de Santos, concejala de Turismo del Ayuntamiento de Segovia, empleó el 13 de diciembre de 2012 para argumentar ante la prensa la puesta en marcha de una ruta turística en la ciudad en torno a la figura de Isabel "La Católica". Otra de las razones fue "la demanda que el éxito de la serie "Isabel" había provocado en la gente", por lo que la emisión de la ficción televisiva se encontraba entre las causas para desarrollar este proyecto.

La ruta "Isabel en Segovia", vigente desde 2013 hasta julio de 2014, tenía una duración de dos horas y quince minutos y un coste general de $13,50 €$ por persona, según fuentes oficiales de Turismo de Segovia. Comenzaba en el acueducto para continuar hasta la casa de los Cabrera-Bobadilla, dos personas claves en la vida y reinado de Isabel, la Plaza de la Reina Doña Juana de Avis, la Casa de Abraham Seneor, la iglesia de San Miguel, donde se proclamó Isabel I como reina propietaria de Castilla, y terminaba en el Alcázar, incluyendo su visita interior.

El impacto de la serie "Isabel" en el turismo cultural de Castilla y León también pudo ser observado en Medina del Campo. A finales de noviembre de 2012, en la Feria Internacional de Turismo de Interior, en adelante INTUR, el Ayuntamiento de Medina del Campo presentó el paquete turístico itinerante "Caminos de una reina", ligado al personaje histórico protagonista de este proyecto. Esta villa vallisoletana decidió aprovechar la emisión de "Isabel" para poner en marcha este producto turístico, todavía hoy comercializado. Además, en 2013 la reina Isabel fue la imagen y principal reclamo turístico de Medina del Campo, puesto que, como declaró su concejal de Turismo en la presentación, José María Magro, lo que se buscaba con estas iniciativas era "ser testigo de los pasos de los visitantes y aficionados de la serie". "Caminos de una reina" ofrece al visitante la posibilidad de apreciar la herencia isabelina en Medina del Campo, al ser un itinerario guiado que incluye la visita conjunta al Palacio Real Testamentario, el Castillo de La Mota y la Colegiata de San Antolín. Se trata de un recorrido de tres horas de duración con un coste general de $8 €$ por persona, estando gestionado por la empresa Aster Magonia y la Oficina de Turismo de la villa.

La ciudad de Valladolid fue una de las últimas en unirse al desarrollo de estas rutas turísticas en torno a la figura de Isabel I de Castilla. Desde el Departamento de Información Turística de la Oficina de Turismo de Valladolid declaran para este trabajo que, aunque el principal motivo de crear una ruta turística en la ciudad sobre esta reina fue conmemorar el 510 centenario de su muerte, la serie de televisión sobre su reinado "sirvió de amplificador e influyó positivamente en las visitas". Un representante del organismo confirma que "fueron muchas las llamadas de gente de otras comunidades interesándose por realizar la visita guiada, ya que desconocían datos históricos que la serie 
puso de relieve". Por tanto, la ficción histórica de RTVE también influyó en el buen desarrollo de este itinerario urbano. De hecho, desde la institución confirman que este mismo hecho "también ocurrió con la emisión de la segunda parte de la serie [refiriéndose a "Carlos, Rey Emperador", la continuación televisiva de "Isabel"], que sirvió como estímulo para la creación de la ruta sobre Carlos V que se realizó en años posteriores".

El producto turístico sobre Isabel La Católica en Valladolid recibió el nombre de "Ruta de Isabel La Católica" y estuvo en vigor desde el 26 de octubre de 2013 hasta marzo de 2014. Consistía en una visita teatralizada programada cada sábado al mediodía que recreaba la visita de la reina a la ciudad de Valladolid con motivo de su boda con el príncipe Fernando, que tuvo lugar en octubre de 1469. Con una duración de dos horas y un coste general de $7 €$, incluía el Campo Grande, el Palacio de Santa Cruz, la Casa de Colón, el Palacio de los Vivero y la Colegiata de Santa María.

Por su parte, dentro del plan anual de visitas guiadas que se organizan desde la Concejalía de Turismo del Ayuntamiento de Ávila se encuentra el itinerario "Ávila Isabelina”. De acuerdo con la información facilitada a este trabajo por el Centro de Recepción de Visitantes de Ávila, dicha ruta comenzó a comercializarse en el año 2013 y actualmente sigue ofreciéndose. "Ávila Isabelina" tiene una duración de tres horas y los participantes, acompañados de un guía oficial de turismo, visitan el Monasterio de Santa Ana o el de Santo Tomás.

Aunque las iniciativas turísticas nacidas a raíz de la serie fueron mayoritariamente municipales, cabe destacar que la Junta de Castilla y León estaba interesada en explotar un turismo cultural ligado a los personajes de su pasado histórico y percibió la oportunidad que existía en el mercado en torno a la figura de Isabel I de Castilla tras el éxito de la primera temporada de la serie "Isabel". Es por ello que decidió presentar en INTUR, a finales de noviembre de 2012, el itinerario cultural "Ruta de Isabel en Castilla y León", sobre el cual se va a profundizar.

\subsection{La Ruta de Isabel en Castilla y León}

La "Ruta de Isabel en Castilla y León" es un itinerario cultural propuesto por la Consejería de Turismo de la Junta de Castilla y León en torno al gran personaje histórico de la reina Isabel "La Católica". La soberana vivió durante gran parte de su vida en diferentes localizaciones de la comunidad y, al tiempo que se emitía en RTVE la serie sobre su vida, la Administración autonómica puso en marcha esta novedosa ruta turística para unir todos esos emplazamientos bajo un mismo camino. Tal y como declaró Alicia García, consejera en aquel momento de Turismo de la Junta de Castilla y León, en la presentación oficial de este producto en INTUR el 24 de noviembre de 2012, la "Ruta Isabel en Castilla y León" es "un ejemplo de colaboración entre administraciones, una apuesta por un producto especializado capaz de contribuir al desarrollo de la cohesión 
territorial de la comunidad, con el fin de que los destinos turísticos se diferencien a través de una estrategia potente". El diseño y organización de la "Ruta de Isabel en Castilla y León" une diferentes puntos turísticos de tres de las nueve provincias de la comunidad, concretamente de las regiones de Valladolid, Segovia y Ávila. Con el itinerario se busca que el visitante recorra desde la localidad de nacimiento de Isabel, pasando por su infancia, su matrimonio con el príncipe Fernando de Aragón, su autoproclamación como reina propietaria de Castilla, rincones esenciales de su reinado, hasta el mismo lugar en el que falleció, hechos históricos que sustentan y justifican la ruta.

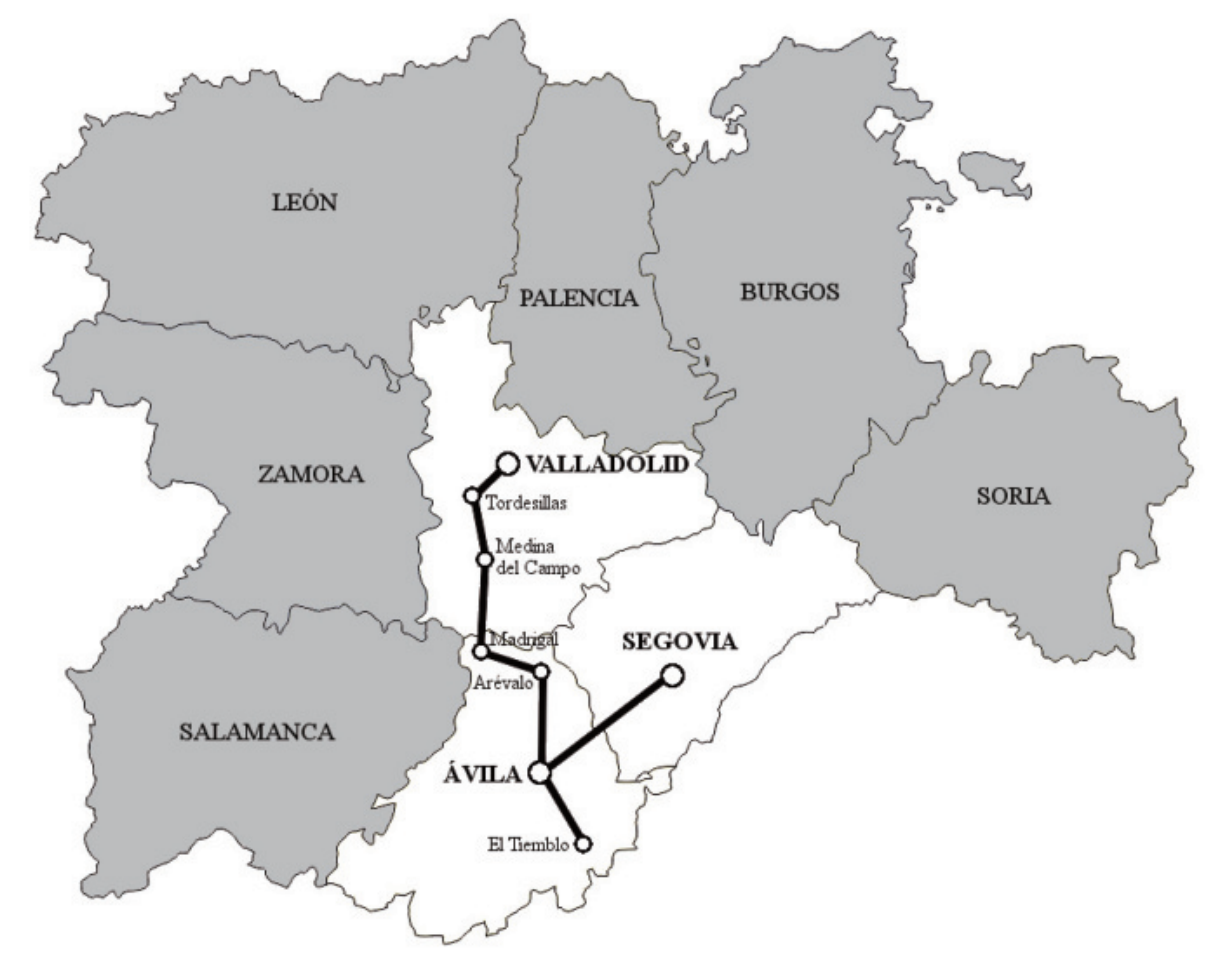

Figura 1. Itinerario de la Ruta de Isabel en Castilla y León.

Fuente: Elaboración propia.

En lo que a la provincia de Ávila se refiere, la propuesta comienza en Madrigal de las Altas Torres, donde nació, y en Arévalo. Estas dos localizaciones son imprescindibles para entender a Isabel I de Castilla, pues allí fue donde vivió su infancia y donde forjó la personalidad que le caracterizó a lo largo de toda su vida, basada en una profunda 
religiosidad católica. La reina se educó con Beatriz de Silva, fundadora de la Orden Concepcionistas que llegaría a ser canonizada, y con los franciscanos de Arévalo, que le inculcaron la virtud de la pobreza (Suárez, 2012). Del mismo modo, el paraje de los Toros de Guisando, en la localidad abulense de El Tiemblo, es otro punto turístico por el que se pasa y clave en la vida de la reina Isabel, pues fue allí donde se realizó el acto entre Enrique IV y ella por el que fue reconocida como princesa heredera de Castilla.

En la provincia de Valladolid la propuesta de la Junta de Castilla y León se centra en visitar la capital, Medina del Campo y Tordesillas. Por un lado, cabe destacar que Isabel entró en la ciudad de Valladolid con solemnidad el 30 de agosto de 1469 para recibir en ella a su futuro esposo, Fernando de Aragón, con el que se casó en octubre de ese mismo año en el Palacio de los Vivero.

Por su parte, Medina del Campo entra a formar parte de la vida de Isabel en marzo de 1468, al haberle cedido su hermano Alfonso el señorío. La decisión sería ratificada más tarde por el rey Enrique IV y la reina no se separaría de la villa hasta el final de sus días, ya que fue en el Palacio Real medinense donde falleció el 26 de noviembre de 1504. En cuanto a Tordesillas, es otra de las localizaciones vallisoletanas clave en este itinerario, al ser en esta villa donde se firmó uno de los documentos más trascendentales del reinado de Isabel I de Castilla, el Tratado de Tordesillas.

La vida de Isabel tampoco se entendería sin la ciudad de Segovia. Siguiendo a Suárez (2012), tanto esta ciudad como Madrid eran, en tiempos de los Trastámara, verdaderas capitales de Castilla gracias a sus alcázares, pero Segovia contaba con un papel preeminente al guardar allí el Tesoro Real. Además, fue en esta misma ciudad donde Isabel se autoproclamó reina propietaria de Castilla en diciembre de 1474 y donde transcurrió buena parte de su vida desde que dejase Arévalo en plena juventud junto a su hermano Alfonso para acudir a la Corte allí asentada.

Es importante destacar que la "Ruta Isabel en Castilla y León" se expuso tan solo un día antes que el Plan de Marketing Turístico de Castilla y León 2013-2014, que apostaba por la internacionalización, la innovación y la colaboración público-privado. Durante la exposición en INTUR, la consejera hizo referencia a los seis millones de turistas interesados en la oferta cultural de Castilla y León y a la trascendencia internacional de la reina Isabel, presentando la ruta como un resorte para atraer mercados exteriores, especialmente el inglés, francés, alemán y estadounidense. Sin embargo, la consejera no quiso olvidar que este producto venía acompañado de actualidad, lo que permitía posicionarse a nivel nacional, en lo que "ayudará mucho una serie de televisión ahora mismo en antena", haciendo clara referencia, aunque sin mencionarla, a la ficción histórica "Isabel", que en aquel momento emitía los capítulos de su primera temporada con gran éxito de audiencia.

La promoción de la ruta no se centró únicamente en INTUR, sino que continuó su andadura a principios de 2013 en la Feria Internacional de Turismo, en adelante FITUR. 
El 1 de febrero de ese mismo año, Turismo de Castilla y León había previsto la visita de los actores protagonistas de la serie "Isabel", Michelle Jenner y Rodolfo Sancho, a fin de apoyar con su presencia en FITUR "la promoción de la ruta de Isabel, un producto turístico cultural especializado que quiere convertirse en una ruta de continuidad dirigida a público familiar" (Junta de Castilla y León, 2013).

La Administración autonómica recurrió de nuevo a la serie más adelante para fomentar la visita a los lugares que componen la ruta a través de una estrategia promocional llevada a cabo junto a RTVE. Durante el verano de 2013, ambos organismos propusieron a los espectadores, en el preámbulo del estreno de la segunda temporada de la ficción, que subieran a sus redes sociales fotografías de lugares isabelinos utilizando la etiqueta \#VeranoIsabel. Los usuarios optarían a dos premios; o un viaje de cuatro días y tres noches por la "Ruta de Isabel en Castilla y León", o un lote de publicaciones relacionadas con la ficción de RTVE.

Las dos acciones anteriores tienen un trasfondo publicitario que confirma la importancia que la serie que estaba siendo emitida en RTVE tenía para la ruta y de cómo la Consejería de Turismo de Castilla y León aprovechó su éxito para promocionar sus diferentes puntos turísticos. Además, estos movimientos estaban en consonancia con la hoja de ruta del Plan de Marketing Turístico de Castilla y León 2013-2014, que contemplaba apostar por "iniciativas novedosas en el ámbito del marketing online y la colaboración público-privada" (Junta de Castilla y León, 2013). Es por ello que, con el objetivo de avanzar hacia el progreso e innovación que propugnaba este plan estratégico, la Junta de Castilla y León decidió apoyar la iniciativa de la empresa Enclave Formación de crear una aplicación para móviles y un portal web oficial con información geolocalizada sobre la "Ruta de Isabel en Castilla y León". El proyecto comenzó a ser desarrollado en abril de 2013 y se presentó en noviembre en Segovia.

Por otra parte, la cohesión territorial y la colaboración entre organismos mediante esta ruta cultural se consiguió a través de la Asociación La Queda de Arévalo, la Semana Renacentista de Medina del Campo, la Asociación Las 4 Puertas de Madrigal de las Altas Torres y el Centro de Iniciativas Turísticas de Tordesillas, que se unieron en 2013 para impulsar el proyecto "Recreaciones Históricas en la Ruta de Isabel en Castilla y León", germen de la actual asociación "Tierra de Ysabel". A través de esa iniciativa, durante los meses de febrero y marzo de 2014 se celebró en Medina del Campo, Arévalo, Madrigal y Tordesillas el evento "Jornadas Isabelinas", cuya finalidad era "estrechar lazos e intercambiar experiencias entre los amantes de la historia" (Ayuntamiento de Tordesillas, 2014). Comenzaron el 8 de febrero de ese año en Arévalo, prosiguieron el 15 de febrero en Medina del Campo, el día 22 en Madrigal y finalizaron el 1 de marzo en Tordesillas.

De acuerdo con el comunicado de prensa de "Recreaciones Históricas en la Ruta de Isabel en Castilla y León", en cada localidad se realizó una breve introducción del municipio y su relación con la reina Isabel, se recrearon momentos importantes de su his- 
toria y se celebró una mesa redonda moderada por un experto en la materia. En el caso de la ponencia que tuvo lugar en Madrigal, intervino Rubén Martín Vaquero, experto medievalista, escritor y asesor histórico de la serie "Isabel", demostrando una vez más el papel que tenía la ficción en la promoción de esta ruta cultural. Las actividades de esta asociación continúan activas gracias a "Tierra de Ysabel" que, según Vinetur (2016), durante el año 2015 contó con una plantilla de 4.750 figurantes y más de 163.000 visitantes en su completa agenda de recreaciones históricas por algunos puntos de la ruta turística. Una de sus últimas grandes iniciativas ha sido la campaña "Todo empezó aquí", que durante el 2016 unió el itinerario isabelino de la Junta de Castilla y León con la "Ruta del Vino de Rueda", dando lugar a una mayor diversificación de productos y una complementación de la oferta, en este caso con la enoturística, fundamental en la comunidad.

\subsection{Los hechos históricos que justifican la Ruta de Isabel en Castilla y León}

El desarrollo de la "Ruta de Isabel en Castilla y León" se pudo llevar a término por la existencia de hechos históricos ligados a la reina Isabel que tuvieron lugar en la comunidad de Castilla y León, sin los cuales no se podría haber realizado el diseño de este itinerario. En la siguiente figura se reflejan algunos de los acontecimientos, siendo clasificados según la provincia en que tuvieron lugar y apuntando también los capítulos de la serie "Isabel" en que fueron narrados, a fin de demostrar la cohesión entre la ruta y la ficción televisiva.

Figura 2. Hechos históricos que justifican la "Ruta de Isabel en Castilla y León"

\begin{tabular}{|l|l|}
\hline \multicolumn{2}{|c|}{ PROVINCIA DE ÁVILA } \\
\hline Fados de Arévalo & $\begin{array}{l}\text { El } 17 \text { de diciembre de } 1467 \text { se celebró en las Casas Reales } \\
\text { de Arévalo el catorce cumpleaños de Alfonso, hermano de } \\
\text { Isabel. La joven fue una de las protagonistas al interpretar, } \\
\text { a modo de fados portugueses, unos versos de Gómez } \\
\text { Manrique. Este momento aparece en el capítulo cuarto } \\
\text { de la primera temporada de "Isabel". }\end{array}$ \\
\hline Actos de Guisando & $\begin{array}{l}\text { Los acuerdos de Cadalso/Cebreros fueron los documentos } \\
\text { por lo que Enrique IV reconoció a su hermana Isabel como } \\
\text { princesa heredera al trono. Ante los verracos de Guisando } \\
\text { se formalizó protocolariamente este hecho en septiembre } \\
\text { de 1468. El momento se reflejó en el capítulo quinto de } \\
\text { la primera temporada de "Isabel". }\end{array}$ \\
\hline
\end{tabular}




\begin{tabular}{|c|c|}
\hline \multicolumn{2}{|r|}{ PROVINCIA DE SEGOVIA } \\
\hline Proclamación de Isabel & $\begin{array}{l}\text { El } 13 \text { de diciembre de } 1474 \text {, tras celebrar los funerales por } \\
\text { Enrique IV, Isabel se despojó de sus paños de luto y } \\
\text { acudió hasta el atrio de la iglesia de San Miguel de Segovia } \\
\text { donde se autoproclamó reina de Castilla. Este hecho se } \\
\text { reflejó en la serie de televisión "Isabel" en el último } \\
\text { capítulo de su primera temporada, siendo el episodio más } \\
\text { visto de entre todas las temporadas de la ficción histórica. }\end{array}$ \\
\hline Concordia de Segovia & $\begin{array}{l}\text { Este acuerdo fue firmado el } 15 \text { de enero de } 1475 \text { en Segovia } \\
\text { y resolvía las demandas de Fernando de tener más } \\
\text { protagonismo en Castilla. Se zanjó, según Suárez (2004), } \\
\text { reconociendo a Isabel como legítima sucesora y propietaria } \\
\text { de la corona, compartiendo sus funciones con Fernando, } \\
\text { su legítimo marido. El momento se recreó en el primer } \\
\text { episodio de la segunda temporada de "Isabel". }\end{array}$ \\
\hline \multicolumn{2}{|r|}{ PROVINCIA DE VALLADOLID } \\
\hline Boda de los Reyes Católicos & $\begin{array}{l}\text { En la Sala Rica del Palacio de los Vivero de Valladolid tuvo } \\
\text { lugar el } 19 \text { de octubre de } 1469 \text { la boda de los Reyes } \\
\text { Católicos. La misa posterior de velaciones se celebró en la } \\
\text { desaparecida Colegiata de Santa María. La boda protagoniza } \\
\text { el capítulo nueve de la primera temporada de "Isabel". }\end{array}$ \\
\hline Tratado de Tordesillas & $\begin{array}{l}\text { El } 7 \text { de junio de } 1494 \text { se firman, según Suárez (2004), dos } \\
\text { tratados en Tordesillas. El primero establecía una partición } \\
\text { del océano Atlántico entre Castilla y Portugal y el segundo } \\
\text { puntualizaciones del Tratado de Alcáçovas. Este momento } \\
\text { se recoge en el capítulo segundo de la última temporada } \\
\text { de la serie "Isabel". }\end{array}$ \\
\hline $\begin{array}{l}\text { Testamento y fallecimiento } \\
\text { de la reina Isabel }\end{array}$ & $\begin{array}{l}\text { Casi cuatro millones de espectadores vieron el último } \\
\text { capítulo de la serie "Isabel", centrado en el testamento y } \\
\text { muerte de la reina. En el Palacio Real de Medina del } \\
\text { Campo, Isabel testó el } 12 \text { de octubre de } 1504 \text { y falleció el } \\
26 \text { de noviembre de ese año. Desde allí partió un cortejo } \\
\text { fúnebre hasta Granada, donde había dispuesto ser sepultada. }\end{array}$ \\
\hline
\end{tabular}

Fuente: Elaboración propia. 


\subsection{Los atractivos turísticos de la Ruta de Isabel en Castilla y León}

Al igual que ocurría con los hechos históricos, sin la existencia de un patrimonio cultural tangible no se hubiera podido construir la "Ruta Isabel en Castilla y León", ya que los diferentes atractivos turísticos de la comunidad ligados a esta reina son la herencia palpable de su huella y, por tanto, pieza clave fundamental para dar forma al diseño de la oferta turística del itinerario. Todos ellos se centran en manifestaciones artísticas, aunque, ante la cantidad de bienes que existen, se ha hecho una selección de los mismos, presentando los considerados más relacionados con la reina, estando nuevamente ordenados según provincia.

La provincia de Ávila tiene presencia en el itinerario isabelino a través de las localidades de El Tiemblo, Arévalo y Madrigal. En ellas tuvieron lugar hechos tan importantes como el nacimiento de la reina Isabel o su reconocimiento como heredera de Castilla en 1468, todos ellos ligados a edificios históricos recogidos y explicados a continuación en la siguiente figura.

Figura 3. Recursos turísticos abulenses de la "Ruta de Isabel en Castilla y León"

\begin{tabular}{|l|l|}
\hline \multicolumn{2}{|c|}{ EL TIEMBLO } \\
\hline Toros de Guisando & $\begin{array}{l}\text { El conjunto escultórico de los Toros de Guisando, datado } \\
\text { de la Edad del Hierro (siglos I-II a.C.), representa cuatro } \\
\text { tallas de verracos esculpidas en granito por los vetones. } \\
\text { Se desconoce su función y ante ellos tuvo lugar, en 1468, } \\
\text { el acto por el cual Enrique IV reconoció a su hermana } \\
\text { Isabel como heredera. }\end{array}$ \\
\hline $\begin{array}{l}\text { Casas Reales } \\
\text { (desaparecidas) }\end{array}$ & $\begin{array}{l}\text { ARÉVALO } \\
\text { pegún Cañas Gálvez (2007), las Casas Reales fueron un } \\
\text { palacio real de los Trastámara situado en la Plaza del Real } \\
\text { y construido en madera y ladrillo. Derruido en 1976, fue } \\
\text { habitado por Isabel "La Católica" durante su infancia en } \\
\text { Arévalo y en él murió su madre, Isabel de Portugal, en } \\
\text { 1496. Los Reyes Católicos nunca olvidaron esta residencia, } \\
\text { ordenando reformas entre 1504 y 1514. Posteriormente, su } \\
\text { nieto Carlos V lo cedió a las monjas cistercienses en 1524. }\end{array}$ \\
\hline Castillo de Arévalo & $\begin{array}{l}\text { La serie "Isabel" comienza con una imagen de este castillo, } \\
\text { a pesar de que la reina nunca vivió en él, sino en las } \\
\text { Casas Reales. La fortaleza fue construida en el siglo XV por } \\
\text { orden de Álvaro de Zúñiga y rematada en estilo mudéjar } \\
\text { por Fernando "El Católico" a principios del XVI. Sirvió de } \\
\text { prisión real hasta finales del siglo XVII, momento de su } \\
\text { abandono, no siendo utilizado de nuevo hasta 1952, como } \\
\text { silo de grano. En el siglo XXI fue restaurado y comenzaron } \\
\text { las visitas turísticas. }\end{array}$ \\
\hline
\end{tabular}




\begin{tabular}{|l|l|}
\hline \multicolumn{2}{|c|}{ MADRIGAL DE LAS ALTAS TORRES } \\
\hline $\begin{array}{l}\text { Convento de Nuestra } \\
\text { Señora de Gracia }\end{array}$ & $\begin{array}{l}\text { El origen de este convento se halla en el Palacio de Juan } \\
\text { II, a pesar de que esta residencia real ya existía en el siglo } \\
\text { XIV, pero fue donde el monarca celebró su boda con Isabel } \\
\text { de Portugal. En él nació su hija, la futura reina Isabel } \\
\text { "La Católica", quien lo reformó. Tras la muerte de los Reyes } \\
\text { Católicos, Carlos V lo cedió a las monjas agustinas. En el } \\
\text { convento todavía se visitan estancias del palacio, como la } \\
\text { alcoba en la que nació la reina Isabel (Cañas Gálvez, 2007). }\end{array}$ \\
\hline $\begin{array}{l}\text { Iglesia de San Nicolás } \\
\text { de Bari }\end{array}$ & $\begin{array}{l}\text { Construida en estilo románico en el siglo XIII y reformada } \\
\text { en mudéjar en el siglo XV, esta iglesia acogió la boda de } \\
\text { Juan II de Castilla e Isabel de Portugal. Conserva ricos } \\
\text { artesonados y la pila bautismal en la que fue bautizada } \\
\text { Isabel "La Católica". }\end{array}$ \\
\hline
\end{tabular}

Fuente: Elaboración propia.

Por su parte, la provincia de Segovia únicamente tiene presencia en la "Ruta de Isabel en Castilla y León" gracias a su capital, Segovia. En ella se produjo un hecho tan fundamental como la autoproclamación de la reina en 1474 y todavía hoy conserva edificios históricos ligados a ella cuya visita es fundamental para entender su reinado. En la Figura 3 se presentan resumidamente algunos de ellos.

Figura 4. Recursos turísticos segovianos de la Ruta Isabel en Castilla y León

\begin{tabular}{|c|c|}
\hline \multicolumn{2}{|r|}{ SEGOVIA } \\
\hline Alcázar & $\begin{array}{l}\text { El origen del alcázar de Segovia, cuyo primer testimonio } \\
\text { escrito data del siglo XII, radica en su uso defensivo, clave } \\
\text { para el dominio de Castilla. Juan II y Enrique IV comenzaron } \\
\text { su reordenación palaciega, continuada por los Reyes } \\
\text { Católicos, que también lo habitaron. En el alcázar celebró } \\
\text { el rey Felipe II su boda con Ana de Austria, monarca que } \\
\text { dotó al edificio del estilo centroeuropeo que presenta por } \\
\text { los agudos chapiteles de pizarra que cubren sus techumbres. } \\
\text { El alcázar perdió su condición de residencia real cuando } \\
\text { Madrid se convierte en capital, pasando a ser prisión real, } \\
\text { y en } 1762 \text { Carlos III funda en él el Real Colegio de Artillería. } \\
\text { Restaurado después de un terrible incendio acaecido en } \\
\text { 1862, de su interior destacan sus techos artesonados } \\
\text { mudéjares, y dependencias como la Sala del Trono, la de } \\
\text { la Galera, la de los Reyes o la subida a la Torre de Juan II. }\end{array}$ \\
\hline
\end{tabular}




\begin{tabular}{|l|l|}
\hline \multicolumn{2}{|c|}{ SEGOVIA } \\
\hline $\begin{array}{l}\text { Palacio Real de San Martín } \\
\text { (desaparecido) }\end{array}$ & $\begin{array}{l}\text { De acuerdo con López Poza (2015) y Merino de Cáceres } \\
\text { (2005), el Palacio Real de San Martín fue fundado por Juan } \\
\text { II de Castilla como aposento privado para su hijo y sucesor. } \\
\text { De grandes dimensiones, en su patio se localizaban las } \\
\text { armas de Enrique IV y la reina Juana de Avis. Fue habitado } \\
\text { por la reina Isabel durante sus estancias en Segovia hasta } \\
\text { los disturbios de 1476, cuando prefirió ocupar el alcázar, } \\
\text { reservado hasta entonces para actos protocolarios. En este } \\
\text { palacio se firmó la Concordia de Segovia y del edificio } \\
\text { solo se conservan las casas de la reina, hoy Museo de } \\
\text { Esteban Vicente. }\end{array}$ \\
\hline Iglesia de San Miguel & $\begin{array}{l}\text { Cerca de la Plaza Mayor se levanta la iglesia de San Miguel, } \\
\text { del siglo XVI, sustituyendo al templo primitivo en cuyo } \\
\text { atrio Isabel "La Católica" se autoproclamó reina de Castilla } \\
\text { el 13 de diciembre de 1474. El edificio actual, levantado } \\
\text { tras el hundimiento del anterior en 1532, consta de una } \\
\text { sola nave gótica, extensa y de gran altura, y dos capillas } \\
\text { laterales, la del Cristo de la Sangre y la funeraria de los } \\
\text { Laguna, que también se utiliza como capilla bautismal } \\
\text { (Sáez y Romero, 1918). }\end{array}$ \\
\hline
\end{tabular}

Fuente: Elaboración propia.

Finalmente, la provincia de Valladolid aparece reflejada en la "Ruta de Isabel en Castilla y León" a través de su capital, Medina del Campo y Tordesillas. En esta provincia tuvo lugar la boda entre la reina Isabel y el príncipe Fernando de Aragón, la firma de documentos importantes de su reinado o su fallecimiento. La Figura 4 recoge los atractivos turísticos ligados a estos hechos.

Figura 5. Recursos turísticos vallisoletanos de la Ruta Isabel en Castilla y León

\begin{tabular}{|l|l|}
\hline \multicolumn{2}{|c|}{ VALLADOLID } \\
\hline Palacio de los Vivero & $\begin{array}{l}\text { El palacio fue levantado en 1440 por Alonso Pérez de } \\
\text { Vivero. En su origen era un edificio gótico-mudéjar } \\
\text { fortificado, pero los elementos defensivos fueron retirados } \\
\text { años después. En él se firmó el 14 de octubre de 1469 el } \\
\text { compromiso entre Isabel de Castilla y Fernando de Aragón, } \\
\text { celebrando la boda cinco días más tarde. Los monarcas } \\
\text { compraron el edificio en 1475 e instalaron en él la Real } \\
\text { Chancillería de Valladolid. De su interior destacan sus } \\
\text { techos y el patio central. Actualmente es la sede del } \\
\text { Archivo Histórico Provincial de Valladolid. }\end{array}$ \\
\hline
\end{tabular}




\begin{tabular}{|c|c|}
\hline \multicolumn{2}{|r|}{ MEDINA DEL CAMPO } \\
\hline Palacio Real Testamentario & $\begin{array}{l}\text { El Palacio Real ocupaba toda una manzana cercana a la } \\
\text { Plaza Mayor de Medina del Campo y de él solo se conserva } \\
\text { un } 15 \% \text {. Fue utilizado por los Reyes Católicos durante sus } \\
\text { estancias en la villa. Uno de los aposentos de este palacio, } \\
\text { configurado como centro de interpretación de la reina Isabel, } \\
\text { conserva una copia del testamento y codicilo de la soberana, } \\
\text { estacando también la sala en la que se recrea la alcoba en la } \\
\text { que la reina expiró, tomando como referencia el cuadro de } \\
\text { Eduardo Rosales "Doña Isabel La Católica dictando su testamento". }\end{array}$ \\
\hline Castillo de La Mota & $\begin{array}{l}\text { Este castillo, que se levanta sobre un antiguo poblado de } \\
\text { la Edad del Hierro, nunca sirvió de residencia para la reina } \\
\text { Isabel, que prefería su palacio real en el centro de la villa. } \\
\text { Sin embargo, bajo su reinado se levantó la barrera defensiva, } \\
\text { continuando la obra iniciada por su padre y su hermano. } \\
\text { Sirvió de prisión real y hoy en día comparte el uso turístico } \\
\text { con la impartición de cursos de formación y congresos. }\end{array}$ \\
\hline Colegiata de San Antolin & $\begin{array}{l}\text { Desde el siglo XII existía en Medina la ermita de San } \\
\text { Antolín, pero durante el reinado de los Reyes Católicos } \\
\text { comenzó una remodelación del templo después de obtener } \\
\text { el Vaticano una bula para establecer en él una colegiata, } \\
\text { levantado un edificio de dimensiones catedralicias en } \\
\text { estilo gótico tardío con tintes renacentistas. } \\
\text { En el siglo XIX perdió el título de colegiata. }\end{array}$ \\
\hline \multicolumn{2}{|r|}{ TORDESILLAS } \\
\hline Casas del Tratado & $\begin{array}{l}\text { Estas dos casas palaciegas unidas, una del siglo XV y la } \\
\text { otra del XVI, sirvieron de marco de negociación y firma } \\
\text { del Tratado de Tordesillas entre Castilla y Portugal. Hoy } \\
\text { en día se utilizan para fines turísticos y culturales. }\end{array}$ \\
\hline Palacio Real (desaparecido) & $\begin{array}{l}\text { Construido a comienzos del siglo XV por orden de Enrique } \\
\text { III de Castilla, el Palacio Real de Tordesillas convirtió a la } \\
\text { villa en un centro de poder durante el reinado de Juan II. } \\
\text { El palacio fue la residencia oficial de los Reyes Católicos } \\
\text { durante la Guerra de Sucesión al trono y en las negociaciones } \\
\text { del Tratado de Tordesillas. Con todo, la principal moradora } \\
\text { del palacio fue la reina Juana, que estuvo recluida en él } \\
\text { durante } 46 \text { años, apartada del gobierno de Castilla por su } \\
\text { hijo, el emperador Carlos V. Ya en el siglo XVIII, Carlos III } \\
\text { ordenó su demolición ante su estado ruinoso. }\end{array}$ \\
\hline
\end{tabular}

Fuente: Elaboración propia. 


\section{Estudio de la demanda turística}

Uno de los aspectos fundamentales a la hora de analizar la demanda turística de un destino es su evolución de visitantes. Para el caso de los puntos turístico que configuran la "Ruta de Isabel en Castilla y León", se analiza el posible impacto que la serie de televisión "Isabel" ha podido tener en cada uno de ellos, una vez hemos comprobado que ha servido de causa directa para su creación. Sin embargo, es necesario matizar que existen factores exógenos que provocan que la repercusión de la ficción no se refleje en total plenitud en las cifras, véase los efectos de la crisis económica de 2008, la celebración de Las Edades del Hombre en alguna de las localizaciones o la ausencia de estadísticas de visitantes precisas en determinados municipios. Cabe destacar también que el estudio de la demanda turística de este itinerario se lleva a cabo emplazamiento por emplazamiento y no globalmente porque, de este modo, se pueden observar mejor las diferencias que se producen entre las grandes ciudades, como Valladolid o Segovia, que de por sí cuentan con curvas de llegada de visitantes más estables en el tiempo, y las localidades más pequeñas, como Medina del Campo, Arévalo o Tordesillas, entre otras, que se pueden llegar a ver más beneficiadas porque no cuentan con una gran afluencia de turistas.

\subsection{Las motivaciones turísticas de los viajeros y su relación con la serie "Isabel"}

Dentro del estudio de la demanda turística, conviene destacar las causas que han llevado a los turistas o visitantes a desplazarse hasta los diferentes destinos que forman parte del itinerario que estamos analizando. Siguiendo a los hermanos García-Mas (2005), la motivación turística explica el porqué del comportamiento del viajero, es decir, todos aquellos factores que activan y dirigen su conducta. Asimismo, es posible hablar de superposición de motivaciones turísticas, al ser estas, fruto de intercalar diferentes deseos y razones, por lo que una motivación puede dar lugar a otras diferentes. Aunque existen tantas motivaciones como razones para emprender un viaje, realmente todas ellas pueden ser clasificadas atendiendo a dos grandes grupos: explícitas, que surgen del entorno en el que se está alienado, e implícitas, basadas en las emociones. Tanto unas como otras preceden a la conducta turística.

En el caso de la "Ruta de Isabel en Castilla y León", las motivaciones de la demanda han sido estudiadas a través de la información y datos obtenidos en entrevistas con oficinas de turismo u organismos turísticos de carácter local. Este trabajo de campo puso de manifiesto que la serie de televisión "Isabel" no solo fue una de los principales factores que animaron a los viajeros a realizar este itinerario, sino que también fue el origen del desarrollo de otras motivaciones secundarias. Buena parte de estas delegaciones de turismo de las localidades de la ruta confirmaron que la mayor parte de los viajeros llegaban sabiendo datos que habían escuchado en la serie de televisión y que querían 
confirmar a través de una visita in situ al lugar de los hechos. "Isabel" ayudó a difundir la envergadura histórica de esta reina y dio a conocer la historia de Castilla, Aragón y el resto de la España del siglo XV como reino y germen de lo que actualmente es el país.

Con la serie no solo hubo un interés por conocer la vida de la soberana, sino también de otros personajes que iban apareciendo en la ficción y que formaban parte de su Corte. Así se encuentra el ejemplo de Tordesillas, el lugar en el que la heredera de Isabel I, Juana "La Loca", estuvo recluida 46 años de su vida y apartada del trono. Tal y como confirman los organismo turísticos del municipio, los visitantes no llegaban para conocer la herencia de la reina Isabel en Tordesillas, sino que principalmente lo hacían por interesarse todavía más por el personaje de Juana que habían visto tanto en "Isabel" como en otras series, véase "Carlos, Rey Emperador".

En este sentido, se podría resumir que las principales motivaciones de la demanda para realizar la ruta isabelina por Castilla y León, de acuerdo con las impresiones recogidas de las entrevistas realizadas a las oficinas de turismo y con la teoría expuesta, son de carácter explícito, basadas todas ellas en un interés por profundizar en la historia y la vida de una reina tan conocida como Isabel "La Católica" a raíz de un factor existente en el entorno, es decir, la serie sobre su vida.

Existen también motivos intrínsecos, ligados a las emociones que el espectador pudiera sentir por el personaje protagonista o por alguno de los secundarios. Así se encuentra el ejemplo de los turistas que se acercaron hasta Tordesillas para interesarse por la hija de Isabel, Juana. Una u otro tipo de motivación, dan sentido al movimiento del turista.

\subsection{Análisis de la demanda en la provincia de Ávila}

Siguiendo el orden del análisis de la oferta que se ha expuesto con anterioridad, comenzamos estudiando el impacto de la serie sobre la demanda turística en los puntos turísticos de la "Ruta de Isabel en Castilla y León" de la provincia de Ávila. En el caso de Arévalo, se ha tomado como referencia la serie temporal de visitantes desde el 2004, como consecuencia de que ese año se celebró en Ávila la exposición de Las Edades del Hombre, hecho que se sucede en 2013 en el propio Arévalo. Los datos han sido facilitados directamente por la Oficina Municipal de Turismo de Arévalo. Uno de los técnicos del mismo organismo declara a este trabajo que "efectivamente el fenómeno "Isabel" se ha dejado notar en Arévalo a nivel turístico, como ya ocurrió en el 2004 con el aniversario de la muerte de la reina". Así lo refleja la curva de visitantes de la Figura 5. Después de un 2013 en el que las visitas se dispararon exponencialmente con la celebración de Las Edades del Hombre, Arévalo recuperó sus visitantes habituales, aunque incrementados respecto a años anteriores a la muestra. 


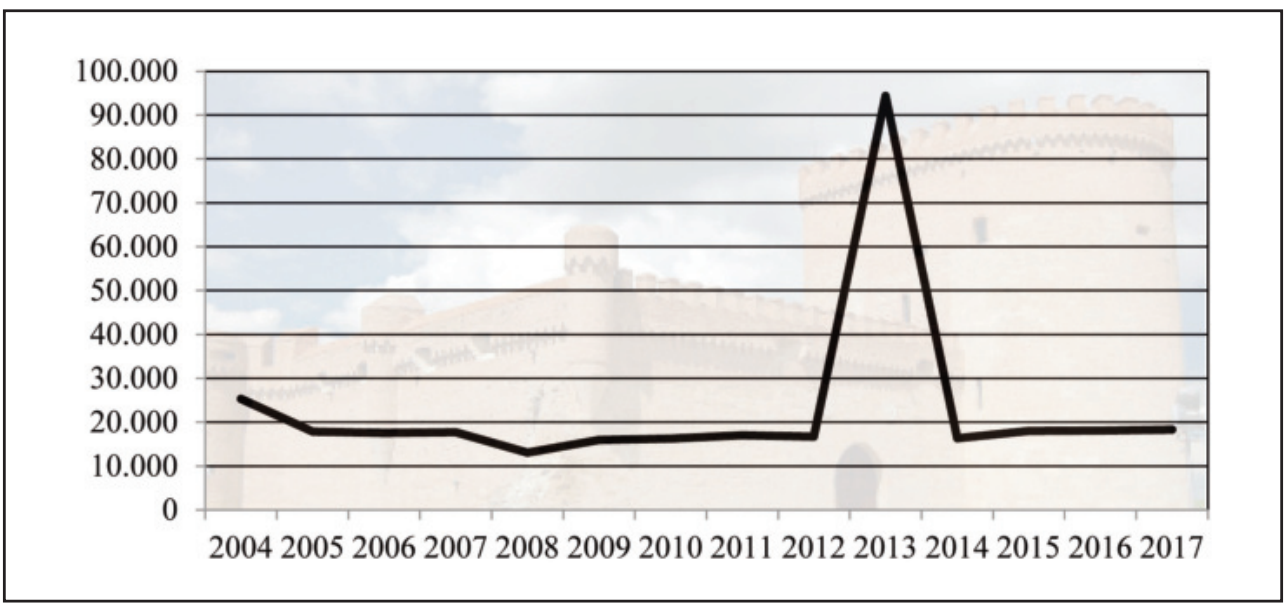

Figura 6. Evolución de visitantes de Arévalo entre 2004-2017.

Fuente: Elaboración propia.

Es arriesgado confirmar que la serie "Isabel" sea la causa de este posterior impulso de visitantes, aunque hay matices puntuales que pueden determinar que sí que influyó de manera positiva. Por ejemplo, el municipio abulense ya cosechó en el cuarto trimestre de 2012 un total de 4.270 visitantes, la cifra más alta de su historia hasta ese momento en ese mismo período sin considerar los datos de 2004, contaminados por el efecto de Las Edades del Hombre. Durante esos meses, la primera temporada de "Isabel" estaba siendo emitida y Arévalo era un nombre recurrente entre los escenarios de la ficción. Es importante destacar que desde la Oficina Municipal de Turismo de Arévalo añaden que los turistas "hoy en día siguen preguntando por la figura de Isabel y por la visita a sitios vinculados con ella. Hemos tenido gente interesada en el tema que ha venido de Portugal, de Estados Unidos y de otros países latinoamericanos". Asimismo, recalcan que este "efecto Isabel" también se vivió en la villa en 2004, cuando se celebró el quinto centenario de su muerte.

Para el caso de El Tiemblo, y en concreto el paraje de los Toros de Guisando, una entrevista con el área de Visitantes Toros de Guisando determinó que la aparición en series como "Isabel" no supone un impacto pronunciado de visitantes, que "es bastante estable en el tiempo, oscilando estos últimos cinco años entre los 12 mil y 14 mil visitantes al año". Visitantes Toros de Guisando encuentran respuesta a esta falta de influencia a la consolidación del monumento, además que consideran que tanto la iniciativa de la ruta isabelina de la Junta de Castilla y León como la serie de RTVE no han dado carácter predominante al lugar, de lo que se deriva que no tenga tanta repercusión sobre la opinión pública. Añaden que "una iniciativa centrada en el monumento de los Toros de Guisando, o en la civilización vetona, afectaría más positivamente al incremento de los visitantes por el carácter especial del monumento". 
Por su parte, Madrigal de las Altas Torres presenta la peculiaridad de que, según conversaciones mantenidas con la Oficina de Turismo de la localidad abulense, han comenzado a contabilizar estadísticas de visitantes en el año 2016, por lo que no es posible establecer un impacto de la serie en base a histórico de viajeros recibidos. Sin embargo, Joana Arias Álvarez, técnico de turismo del Ayuntamiento, sí que facilita a este trabajo apuntes cualitativos sobre el tema objeto de estudio. En cuanto a la repercusión de la serie "Isabel" en la villa, no dudó en afirmar que sí que se percibió un aumento notable en llegada de visitantes. A pesar de ello, hoy en día son pocas ya las personas que llegan a Madrigal derivadas de la ficción históricas de RTVE, aunque todas las que recibieron a raíz de verla cada semana en televisión "ni siquiera conocían Madrigal ni habían oído hablar de la localidad".

\subsection{Análisis de la demanda en la ciudad de Segovia}

Por otro lado, Segovia es, a parte de punto de paso de la "Ruta de Isabel en Castilla y León”, Ciudad Patrimonio de la Humanidad. No es de extrañar, por tanto, que tenga un considerable número de turistas interesados en visitar sus recursos turísticos. Tomando como referencia el período 2010 en adelante, y a pesar de las ligeras bajadas en puntuales años, la capital segoviana presenta una curva de viajeros creciente, registrando el máximo de ese conjunto en 2017, con 269.476 viajeros. Observando la Figura 6, en la que se recoge gráficamente la evolución del histórico de visitantes, es importante tener en cuenta que no existen, a priori, suficientes evidencias de que la aparición del nombre de Segovia y su alcázar en la serie "Isabel" ayudase al incremento de viajeros a la ciudad. De hecho, el aumento más significativo se produjo una vez la ficción había terminado de emitirse, cuando finalizó su última y tercera temporada en 2014.

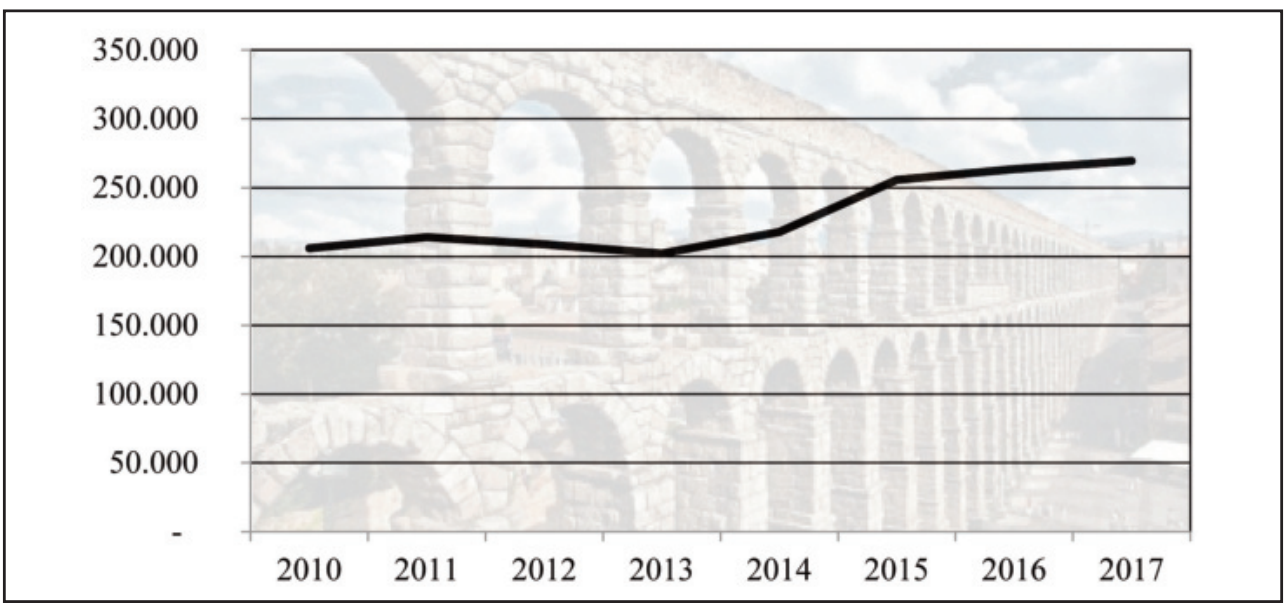

Figura 7. Evolución de viajeros recibidos en Segovia entre 2010-2017.

Fuente: Elaboración propia. 
Es importante analizar, en este sentido, los datos específicos de recursos turísticos segovianos vinculados a Isabel "La Católica", siendo el principal elemento el alcázar de la ciudad. En siete años ha conseguido un aumento del 38\% de sus visitantes, hasta alcanzar también el máximo en 2017, con 269.476 entradas. Durante el período en que se emitió la serie, 2012-2014, los espectadores visualizaron cada semana multitud de panorámicas del alcázar, siendo recreadas para conseguir el estilo que tenía en tiempos de los Reyes Católicos. A pesar de ello, no se aprecia en los datos subidas de visitantes importantes, sino que incluso existe una bajada de 2012 a 2013, tal y como se puede observar en la Figura 7, donde se compara con los visitantes de la catedral.

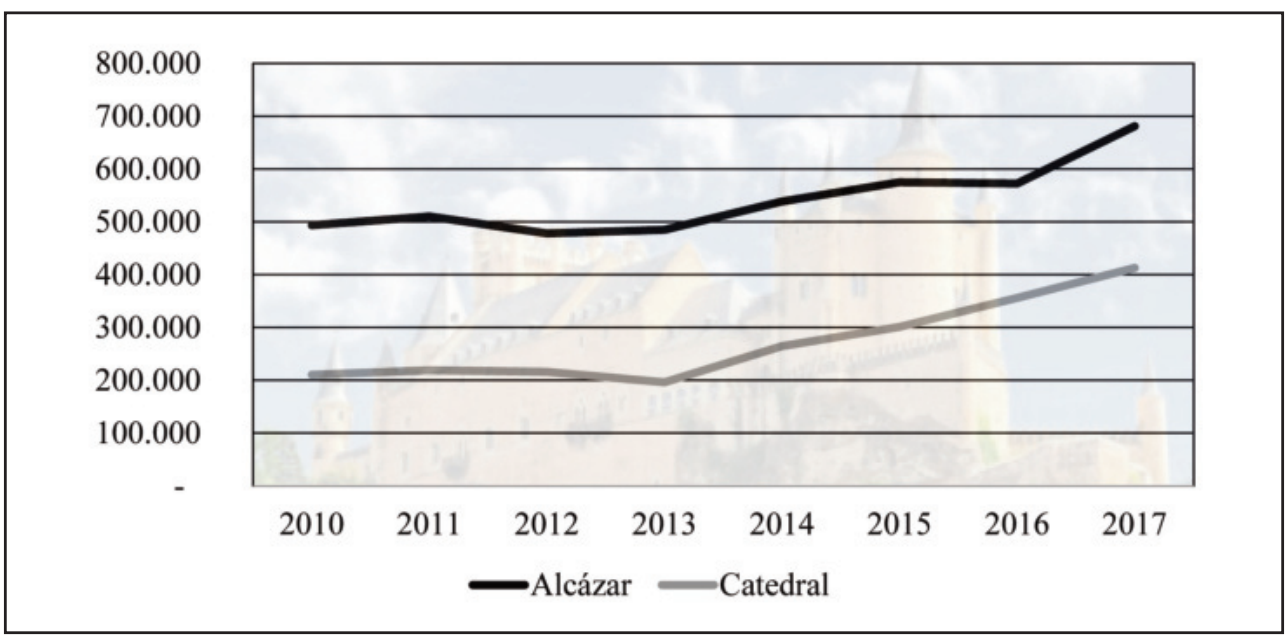

Figura 8. Evolución de visitantes del alcázar y la catedral de Segovia 2010-2017.

Fuente: Elaboración propia.

En cuanto a la ruta "Isabel en Segovia" de la que se habló anteriormente, tan solo estuvo vigente año y medio. En 2013 fue adquirida por 714 personas, siendo, de acuerdo con el Boletín Informativo Observatorio Turístico de Segovia 2013, la segunda ruta más demandada por los visitantes de entre las que se ofrecían desde la Oficina de Turismo. En las conclusiones del mismo informe (2013), ya se apuntaba que el caso de la ruta de Isabel demuestra que "el hecho de que la empresa esté atenta a los intereses del público a la hora de elaborar los nuevos productos es clave para su éxito”. Sin embargo, en los siete meses que la ruta estuvo vigente en 2014 tan solo consiguió reunir a 315 interesados, siendo retirada en el mes de julio "como consecuencia del decreciente interés suscitado por la serie "Isabel'" (Boletín Informativo Observatorio Turístico de Segovia, 2014, p. 6). Todo ello viene a demostrar que, aunque la ciudad de Segovia trató de sumarse al éxito de la ficción histórica de RTVE, no consiguió realmente una repercusión tan exponencial como se pretendía. 


\subsection{Análisis de la demanda en la provincia de Valladolid}

Por otro lado, en lo que a la provincia de Valladolid se refiere, el análisis se inicia con la capital. Aunque en la evolución de la llegada de viajeros a Valladolid que se ve en la Figura 8 (teniendo como fuente de información el Instituto Nacional de Estadística) se aprecia que a partir de 2012, año del comienzo de la emisión de la serie "Isabel", se produce un incremento positivo mantenido en el tiempo. No existen en el entorno suficientes pruebas que puedan dictaminar que esto se deba al efecto de la ficción histórica de RTVE. Conviene recurrir para ello a estadísticas más precisas.

Se ha tratado de estudiar el recurso turístico ligado a la reina Isabel que conserva la ciudad de Valladolid, es decir, el Palacio de los Vivero, hoy en día sede del Archivo Histórico Provincial de Valladolid y del Archivo de la Real Chancillería. Aunque es posible visitarlo, Ángel Laso Ballesteros, director del Archivo Histórico Provincial de Valladolid, aclara para este trabajo que "no se realiza un control numérico de los visitantes, por lo que no se elaboran estadísticas". Cuando es preguntado por el impacto que la serie "Isabel" pudo tener en las visitas al Palacio, aclara que bajo su impresión personal "sí que hubo un mayor interés en visitar este lugar". No es de extrañar, ya que, aunque no se utilizó como lugar de rodaje, su nombre fue protagonista durante todo un capítulo entero de la serie, aquel en el que se narra la boda de los Reyes Católicos.

Por otra parte, y en relación a la entrevista con el Departamento de Información Turística de la Oficina Turismo de Valladolid, la "Ruta de Isabel La Católica" de Valladolid que se prolongó durante seis meses entre 2013 y 2014 fue adquirida por aproximadamente 800 personas, dato muy superior en comparación con el que se obtuvo en otras rutas municipales, como la ya comentada de Segovia.

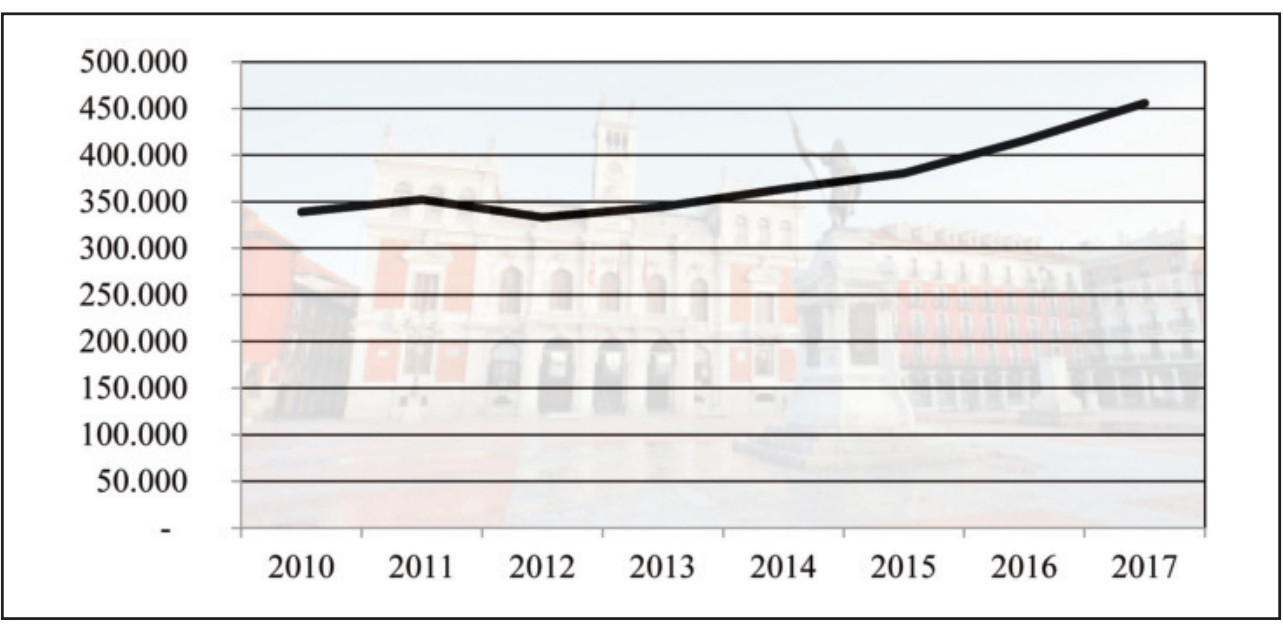

Figura 9. Evolución de viajeros recibidos en Valladolid entre 2010-2017. 
Para el caso de Medina del Campo, el análisis de visitantes contempla los dos grandes recursos turísticos ligados a Isabel "La Católica", como son el Castillo de La Mota y el Palacio Real, así como el producto turístico "Caminos de una Reina", ofrecido por Turismo de Medina del Campo y la empresa Aster Magonia, compañía dedicada a la gestión y dinamización de los espacios culturales de la villa vallisoletana. Sin embargo, el estudio se centra en el edificio palaciego. Es importante destacar que Medina del Campo acogió, junto a Medina de Rioseco, la exposición de Las Edades del Hombre en 2011. Es por ello que en la Figura 9, que recoge la evolución de visitantes de los tres recursos turísticos facilitada por Aster Magonia, se observa un incremento considerable de visitantes ese mismo año en el Palacio Real y el Castillo de La Mota. El año siguiente, los dos recursos volvieron a situarse en los datos que venían teniendo antes de la celebración de la muestra.

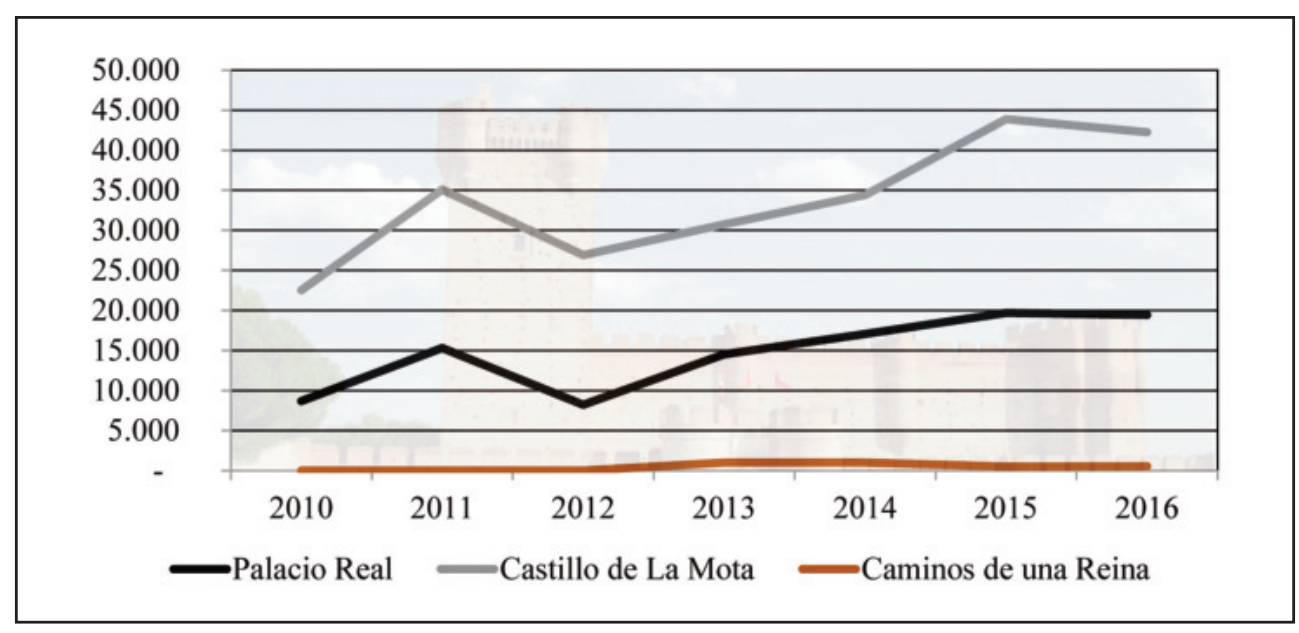

Figura 10. Visitantes de 2010-2016 en los recursos turísticos de Medina del Campo.

Fuente: Elaboración propia.

En 2012, cuando la serie de televisión "Isabel" fue estrenada, ambos edificios comenzaron una tendencia ascendente hasta el 2015, justo un año después de que finalizara la emisión de esta ficción histórica, cuando se estancaron manteniendo los grandes datos en los que habían llegado a situarse. Además, en 2012 fue puesto en marcha el producto turístico "Caminos de una Reina", que, aunque comenzó con números muy bajos y escasos, consiguió pasar de 21 visitantes en su estreno hasta los 1.032 cosechados un año después. Su éxito, ligado íntimamente al de la serie, ha hecho posible que todavía hoy continúa comercializándose.

Es importante analizar especialmente el histórico de visitantes del Palacio Real o Testamentario de Medina del Campo, al ser el principal centro de interpretación de la reina 
Isabel "La Católica" en España. Aislando el dato de 2011, influido por los visitantes de Las Edades del Hombre, fue en 2013 cuando se produjo un aumento del 76\% de visitantes respecto a los datos que venía acumulando, que se movían en torno a las 8.000 personas. En aquel momento, el nombre de Medina del Campo participaba activamente en la serie de RTVE, siendo mencionado sobre todo en su tercera y última temporada, emitida en 2014, cuando el palacio rompió la barrera de los 15.000 visitantes, comenzando una carrera ascendente que le ha hecho rozar los 20.000.

Finalmente, de la provincia de Valladolid únicamente queda por comentar Tordesillas, el tercer punto vallisoletano de la "Ruta de Isabel en Castilla y León". Para poder obtener datos de visitantes se recurrió directamente a la Oficina de Turismo de la localidad, quien a su vez los remitió de la Alcaldía de Tordesillas. Aunque existió un leve aumento de visitantes a partir de 2012, nada hace intuir, a simple vista, que se deba a la serie "Isabel". El nombre de Tordesillas apareció en contadas ocasiones en la ficción, aunque sí es cierto que protagonizó al completo un capítulo de la serie, como fue así el de la firma del Tratado en 1494. Tordesillas se movía en cifras que rondaban los 40.000 visitantes, aunque rompió la barrera en 2016 cuando alcanzó las 53.738 personas que visitaron la villa vallisoletana. En la siguiente Figura se puede contemplar la curva de visitantes de la localidad desde el año 2010.

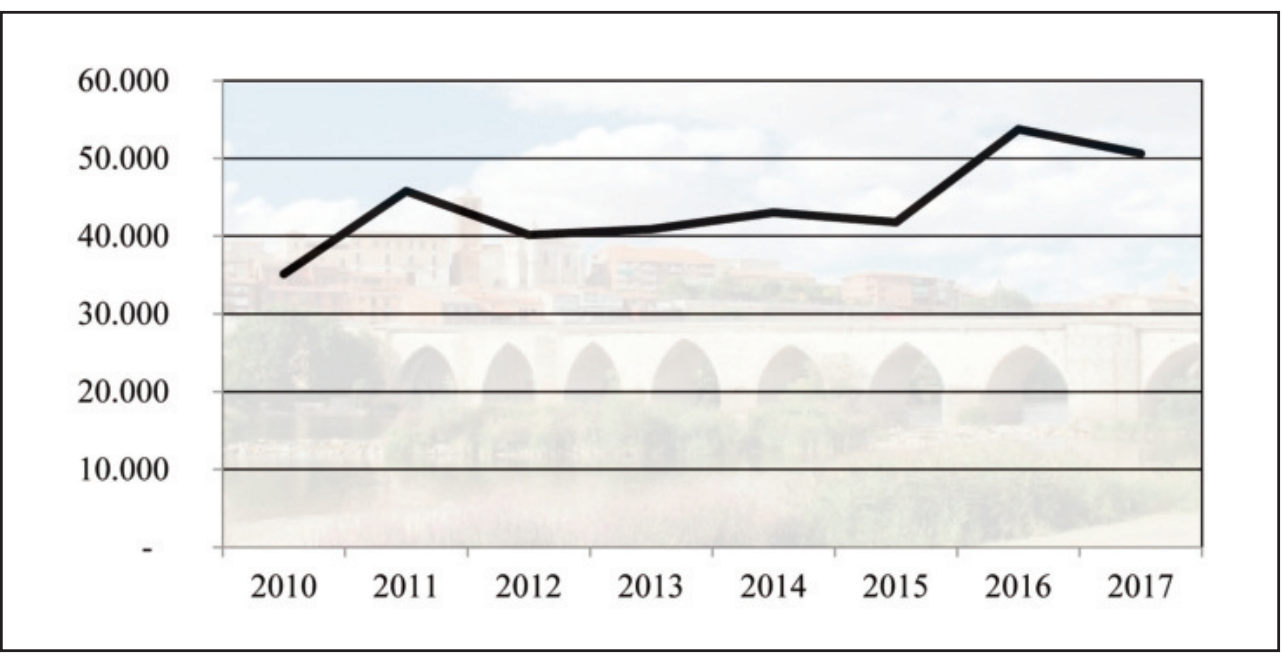

Figura 11. Evolución de visitantes de Tordesillas entre 2010-2017.

Fuente: Elaboración propia.

Por otra parte, el Museo del Tratado, que podría ser el edificio más vinculado a los Reyes Católicos en Tordesillas, puesto que el Palacio Real fue derruido siglos atrás, no lleva a cabo estadísticas de visitantes ya que la entrada es libre, y no contabilizando 
tampoco un registro comercial de tickets expedidos, tal y como confirman desde el mismo Ayuntamiento. Es por ello que no se puede conocer con certeza si este recurso turístico pudo ver aumentado su demanda turística a raíz de la emisión de la serie sobre la reina de Castilla.

\section{Discusión y conclusiones del estudio}

El trabajo que se ha llevado a cabo ha puesto de manifiesto que la política turística de Castilla y León está planteada adecuadamente, estando basada en el desarrollo de itinerarios culturales en torno a su historia, como así fue la creación de la "Ruta de Isabel en Castilla y León" en 2012. Estas iniciativas tienden a ser un valor seguro por las características del viajero que acoge Castilla y León, que responde claramente a una tipología de visitante interesado en realizar rutas culturales, utiliza su propio coche como medio de transporte y su principal actividad es visitar monumentos.

Por otro lado, el patrimonio cultural es un pilar fundamental en Castilla y León tal y como se demuestra con el Plan PAHIS 2020. Se trata de una de las regiones de España con más número de Bienes de Interés Cultural y la primera en aglutinar recursos catalogados como Patrimonio de la Humanidad por la UNESCO. Este legado histórico y patrimonial tan importante, ha sido la causa del arraigo de un fuerte turismo cultural en la comunidad en torno al mismo, haciendo de esta actividad una de las fuentes principales de riqueza de su economía.

Del mismo modo, con Castilla y León y el caso de la serie "Isabel" se puede observar la convergencia entre la industria turística y la audiovisual. Los destinos turísticos han comenzado a incluir su aparición en series de televisión dentro de su estrategia de marketing y promoción para diferenciarse en un entorno muy competitivo. Los espectadores sienten la necesidad de visitar los lugares en los que se desarrolla la trama de una serie y los agentes turísticos utilizan esa oportunidad para incrementar la llegada de turistas y diversificar la oferta. De este modo, se puede hablar de sinergias reales entre el turismo y el mundo audiovisual.

La emisión de la serie "Isabel" y la aparición de diferentes puntos de Castilla y León en ella conllevó al nacimiento de un interés en el espectador por visitar esos rincones. De este modo, se crearon productos turísticos a nivel local para atraer a la demanda, tales como las rutas centradas en Isabel por el centro de Segovia, Ávila o Valladolid. La propia Junta de Castilla y León puso en marcha el itinerario "Ruta de Isabel en Castilla y León" a nivel autonómico. Aunque desde el organismo no se afirme claramente que trataron de aprovechar el éxito de la serie, realmente fue así, ya que desplegaron acciones posteriores de promoción de la ruta con los actores protagonistas de la serie e, incluso, con la propia RTVE. 
Aunque la "Ruta de Isabel en Castilla y León" es el principal ejemplo que muestra la diversificación de la oferta que tuvo lugar en la comunidad autónoma a raíz de la emisión de la serie, el itinerario fue motor para el desarrollo de otras iniciativas ligadas a él. La comunidad consiguió alcanzar cohesión territorial y colaboración entre organismos mediante esta ruta cultural, gracias a las diversas actividades que se organizaron alrededor de ella, implicando cooperación entre municipios. Como fue el caso de las "Recreaciones Históricas en la Ruta de Isabel en Castilla y León", germen de la actual asociación "Tierra de Ysabel". Esto es algo fundamental para una región en la que existe una alta dispersión en el reparto de su población, concentrada mayoritariamente en las áreas urbanas de las capitales de provincia.

La serie "Isabel" generó una motivación para viajar a Castilla y León, una inquietud en los espectadores y futuros turistas por ampliar información sobre los acontecimientos que observaban en televisión. No buscaban solamente conocer más en profundidad la biografía de la reina, sino también de las personas que formaron parte de su vida y presentes de igual modo en multitud de lugares.

Todo ello tuvo una huella en las estadísticas de visitantes de los puntos turísticos que forman la "Ruta de Isabel en Castilla y León", tomada como referencia para este estudio. En este sentido, es mucho más palpable el impacto en las localidades más pequeñas que en las capitales de provincia, que suelen contar con datos más constantes y estables en el tiempo. Medina del Campo es la localidad de la "Ruta de Isabel en Castilla y León" que más se benefició de la aparición de su nombre en la serie "Isabel", aumentando copiosamente sus estadísticas de llegadas de visitantes.

Tenemos que hacer especial mención del Palacio Real Testamentario de Medina del Campo, el lugar de fallecimiento de la reina Isabel y convertido hoy en día en el único centro de interpretación de su figura en España. Este edificio sirve de ejemplo para saber si verdaderamente la serie de televisión ha tenido un impacto en el turismo o no, ya que es el único lugar en todo el país en el que se presenta la vida y reinado de esta monarca desde un punto de vista museístico. Como se vio, a raíz de la emisión de la serie se ha llegado a duplicar el número de entradas, lo que viene a demostrar que verdaderamente la serie ha beneficiado a los puntos isabelinos. Desde su apertura en 2004, nunca antes se habían registrado unas estadísticas tan potentes, ni siquiera cuando la villa de Medina del Campo acogió en 2011 Las Edades del Hombre. De hecho, al año siguiente el monumento volvió a recuperar sus datos habituales, siendo ya en 2013 cuando, en pleno apogeo de la serie de televisión, empezó su camino ascendente hasta rozar casi los 20.000 visitantes en 2015.

En definitiva, se confirma que la utilización de la serie de televisión como herramienta de promoción de un destino turístico es efectiva, no siendo necesario que sea una ficción internacional de amplio alcance para que esto ocurra. Con el caso de Castilla y León, se ha demostrado que una serie española como "Isabel" puede ayudar a 
la diversificación de la oferta turística y a generar motivaciones en los espectadores para acudir hasta un determinado emplazamiento y visitarlo. Todo ello puede ocurrir solamente si los organismos turísticos consiguen aprovechar las oportunidades del entorno y poner en marcha proyectos rentables que generan riqueza para el destino.

\section{Bibliografía}

Cascajosa Viriano, C., 2016. La cultura de las series. Barcelona: Laertes.

Castaño, J.M., 2015. Psicología Social de los Viajes y del Turismo. Madrid: Thomson.

García-Más, A., García-Más, A., 2005. La mente del viajero. Características psicológicas de viajeros y turistas. Madrid: Thomson Paraninfo.

Herrero Prieto, L.C., 2000. Turismo cultural: el patrimonio histórico como fuente de riqueza. Valladolid: Fundación del Patrimonio Histórico de Castilla y León.

Martínez Puche, A., Martínez Puche S., Prieto Cerdán, A., 2012. Territorios de cine: desarrollo local, tipologías turísticas y promoción. Alicante: Publicaciones Universidad de Alicante.

Martínez Puche, S., 2010. "Reposicionamiento de la imagen turística de Brujas a través del cine: de ciudad de cuento a ciudad de thriller". Pensar la publicidad. Vol. 4, no 1: 147-166.

Morère Molinero, N., Perelló Oliver, S., 2013. Turismo cultural. Patrimonio, museos y empleabilidad. Madrid: Fundación EOI.

Querol, M.A., 2010. Manual de gestión del Patrimonio Cultural. Madrid: Akal.

Suárez, L., 2004. Isabel I, Reina. Barcelona: Ediciones Folio/Biblioteca ABC.

\section{Otros recursos}

"Anuario de Estadísticas Culturales". Ministerio de Educación, Cultura y Deporte. Ref. 07/12/2017 [https://www.mecd.gob.es/servicios-al-ciudadano/estadisticas/cultura/mc/naec/portada.html].

Araújo Vila, N., Fráiz Brea, J.A., 2013. "Las series audiovisuales como herramienta promocional de un destino turístico: el caso de España". Investigaciones europeas de dirección y economía de la empresa. Vol. 19, no 1: 8-15. Ref. 25/11/2017.

[http://www.elsevier.es/es-revista-investigaciones-europeas-direccion-economia-empresa-345pdf-S1135252312000317-S300]. 25/11/2017.

"Boletines de Coyuntura". Turismo Castilla y León. Ref. 22/03/2018. [http://www.turismocastillayleon.com/es/espacio-profesionales/boletines-coyuntura].

"Boletines Observatorio Turístico de Segovia". Turismo de Segovia. Ref. 12/02/2018. [http://www.turismodesegovia.com/observatorio-turistico/boletines/].

"Caminos de una reina". Turismo de Medina del Campo. Ref. 10/01/2018. [http://medinadelcampo.es/la-villa-de-los-mil-planes/34-rutas-de-medina/77-caminos-de-unareina]. 
"Caminos de una reina". Turismo Provincia de Valladolid.

[http://www.provinciadevalladolid.com/es/medina-campo/caminos-reina]. 10/01/2018.

"Castilla y León rentabiliza su presencia en Fitur a través de la apuesta y el apoyo a la comercialización". 15/01/2018. Comunicación Junta de Castilla y León.

[http://comunicacion.jcyl.es/web/jcyl/Comunicacion/es/Plantilla100Detalle/128137205 1501/_/1284255764110/Comunicación].

"Casas del Tratado de Tordesillas". Turismo Provincia de Valladolid. Ref. 21/01/2018.

[http://www.provinciadevalladolid.com/es/tordesillas/casas-tratado-tordesillas].

"Castilla y León rentabiliza su presencia en Fitur a través de la apuesta y el apoyo a la comercialización”. Comunicación Junta de Castilla y León. Ref. 15/01/2018.

[http://comunicacion.jcyl.es/web/jcyl/Comunicacion/es/Plantilla100Detalle/12813720 51501/_1284255764110/Comunicación]. "Castilla y León y RTVE invitan a vivir este verano una 'Experiencia Isabelina”". Comunicación Junta de Castilla y León. Ref. [http://comunica cion.jcyl.es/web/jcyl/Comunicacion/es/Plantilla100Detalle/1281372057130/_/1284278153092/ Comunicación]. 15/01/2018.

"Cine y Turismo". Spain Film Commission. Ref. 03/01/2018.

[http://www.shootinginspain.info/es/cine-y-turismo]. "Colegiata de San Antolín". Turismo Medina del Campo. Ref. [http://medinadelcampo.es/colegiata-de-san-antolin].

"Comienzan en Arévalo las jornadas para promocionar las recreaciones de la Ruta Isabel". RTVCYL Ref. [http://www.rtvcyl.es/Noticia/1160F687-E862-B26B-23742817A288CE79/comienzan/arevalo/jornadas/promocionar/recreaciones/ruta/isabel] 15/01/2018

"Cultura y ocio 2017". INE. Ref. [http://www.ine.es/prodyser/pubweb/anuario17/anu17_04cultu.pdf] $25 / 11 / 2017$.

"El cine en Andalucía. Filmografía". Andalucía Film Commission. Ref. 13/10/2017. [www.andaluciafilm.com/index.php/cine_andalucia/detalle_pelicula/Peliculas/779].

"El Plan de Marketing Turístico será la hoja de ruta de la promoción y comercialización en mercados nacionales e internacionales". Junta de Castilla y León. Ref. 14/01/2018.

[http://www.jcyl.es/web/jcyl/Gobierno/es/Plantilla100Detalle/1246464876027/_/128424 7655786/Comunicación].

"España - Registro de la Memoria del Mundo". UNESCO. Ref. 27/11/2017.

[http://www.unesco.org/new/es/communication-and-information/memory-of-the-world/register/access-by-region-and-country/es/].

"Film commissions". Ministerio de Educación, Cultura y Deporte. Ref. 13/10/2017.

[https://www.mecd.gob.es/cultura-mecd/areas-cultura/cine/directorio-cine/film.html]. García Zarza, E. (2002).

"El turismo cultural en Castilla y León. El caso singular de Las Edades del Hombre". Cuadernos de Turismo. № 10: 23-68. Ref. 15/11/2017.

[http://revistas.um.es/turismo/article/view/21871/21161].

J. R. (2012). Caminos de una Reina llega a Medina del Campo. Expreso. Ref. 11/01/2018. [http:// www.expreso.info/noticias/espana/29962_caminos_de_una_reina_llega_medina_del_campo]. "La Junta apoya el desarrollo de una aplicación para móviles y un 'geoportal' de la ruta de 
Isabel la Católica en Castilla y León”. Comunicación Junta de Castilla y León. Ref. [http:// comunicacion.jcyl.es/web/jcyl/Comunicacion/es/Plantilla100Detalle/1281372051501/__ 1284293045464/Comunicación]. 15/01/2018.

"La Junta presenta 'Tronos que comparten historia y presente' para difundir la relevancia de Fernando III y Carlos I en la historia de la Comunidad". Comunicación Junta de Castilla y León. Ref. 17/11/2017. [http://comunicacion.jcyl.es/web/jcyl/Comunicacion/es/Plantilla100Detalle/1284281873211/_/1284718682780/Comunicación].

"La Junta se adhiere a la Red de Cooperación de las Rutas Europeas de Carlos V para su promoción en Castilla y León". Comunicación Junta de Castilla y León. Ref. 17/11/2017. [http:// comunicacion.jcyl.es/web/jcyl/Comunicacion/es/Plantilla100Detalle/1281372051501 /_/1284761529207/Comunicación] Mallor, E., González-Gallarza, M., Fayos Gardó, T. (2013). "¿Qué es y cómo se mide el Turismo Cultural? Un estudio longitudinal con series temporales para el caso español". Pasos. Vol. 11, no 2: 269-284. Ref. [http://www.pasosonline.org/Publicados/11213/PS0213_01.pdf]. 17/11/2017.

MERINO, J.M., 2005. "El Palacio Real de Segovia, un monumento que desaparece". Salvar patrimonio. Ref. 19/01/2018. [http://www.salvarpatrimonio.org/cronicas/palacio-real-segovia.html].

"Palacio de los Vivero - Chancillería". Valladolid, portal de tu ciudad. Ref. 21/01/2018. [http://valladolid.portaldetuciudad.com/es-es/informacion/palacio-de-los-vivero-chancilleria-de014_233_2_1368.htmll.

"Plan de Marketing Turístico de Castilla y León 2013-2014". 14/01/2018. Turismo de Castilla y León. Ref. [http://www.turismocastillayleon.com/es/espacio-profesionales/planes-estrategicos/plan-marketing-turistico-castilla-leon-2013-2014].

Recreaciones Históricas en la Ruta de Isabel en Castilla y León (2014). Este sábado comienzan las Jornadas Isabelinas (nota de prensa). Ref. 16/01/2018. [http://www.cit-tordesillas.es/doc/ 654e5e5e3dc88c33ecbc80f1bc0de0f8.pdf].

"Ruta Isabel, todos los domingos". Turismo de Segovia. Ref. 10/01/2018. [http://www.turismodesegovia.com/ruta-isabel-todos-los-domingos/].

Sáez y Romero, M., 1918. Las calles de Segovia: noticias, tradiciones y curiosidades. Segovia: Antonio San Martín. Ref. 19/01/2018. [http://bibliotecadigital.jcyl.es/i18n/catalogo_imagenes/ grupo.cmd?path=10066070].

Segovia al día SGD, 2012. Ayuntamiento de Segovia. Presentación ruta turística Isabel (archivo de vídeo) ]. 11/01/2018. Ref. [https://www.youtube.com/watch?v=QYUB6xNvB5o].

TelemedinaCanal9, 2012. INTUR 2012 (archivo de vídeo). 11/01/2018. Ref. [https://www.youtube.com/watch?v=_0XJfPTtetU].

"Todo empezó aquí: saborea la tierra de Ysabel con la Ruta del Vino de Rueda". 22/01/2018. Vinetur. Ref. [https://www.vinetur.com/2016012122459/todo-empezo-aqui-saborea-la-tierra-deysabel-con-la-ruta-del-vino-de-rueda.html]. 
